\title{
Composição mineral em genótipos de batata-doce de polpas coloridas e adequação de consumo para grupos de risco
}

\author{
Mineral composition of sweet potato genotypes with coloured pulps and their \\ consumption adequacy for risk groups
}

\author{
Márcia Vizzotto ${ }^{1 *}$, Elisa dos Santos Pereira ${ }^{2}$, Luis Antonio Suita de Castro ${ }^{1}$, Chirle de Oliveira Raphaelli², \\ Ana Cristina Krolow ${ }^{1}$ \\ 1 Empresa Brasileira de Pesquisa Agropecuária (Embrapa Clima Temperado), Pelotas/RS - Brasil \\ 2 Universidade Federal de Pelotas (UFPel), Programa de Pós-graduação em Ciência e Tecnologia de Alimentos, Pelotas/RS - Brasil
}

\section{*Corresponding Author}

Márcia Vizzotto, Empresa Brasileira de Pesquisa Agropecuária (Embrapa Clima Temperado), Laboratório de Ciência e Tecnologia de Alimentos, Rodovia BR-392, km 78, CEP: 96010-971, Pelotas/RS - Brasil, e-mail: marcia.vizzotto@embrapa.br

Cite as: Mineral composition of sweet potato genotypes with coloured pulps and their consumption adequacy for risk groups. Braz. J. Food Technol., v. 21, e2016175, 2018.

Received: Dec. 01, 2016; Accepted: Aug. 29, 2017

\section{Resumo}

Este estudo objetivou quantificar minerais presentes em genótipos de batata-doce de polpa colorida, selecionados e cultivados pela Embrapa (Empresa Brasileira de Pesquisa Agropecuária), no sul do Rio Grande do Sul, bem como verificar o percentual de adequação de consumo em grupos de risco nutricional. Genótipos de batata-doce cultivados no Banco Ativo de Germoplasma - polpa branca (Rubissol, ILS 12, ILS 10, ILS 24); polpa creme (Cuia, ILS 03, ILS 44); polpa amarela/laranja (Amélia e Beauregard); polpa roxa (ILS 56, ILS 16 e ILS 71) - foram analisados em triplicata. Os minerais foram quantificados por espectrometria de absorção atômica e os resultados foram expressos em miligrama do mineral correspondente a $100 \mathrm{~g}^{-1} \mathrm{de}$ amostra úmida. Cálculos dos percentuais de adequação da ingestão diária recomendada de cada genótipo para grupos de risco (crianças entre 4 e 8 anos e gestantes entre 19 e 30 anos), com base no consumo de uma porção média de $200 \mathrm{~g}$ diários, foram realizados. As batatas-doces apresentaram grande variação na quantidade de minerais entre os genótipos e o potássio foi o mais abundante em todos estes, com destaque para os genótipos ILS 44, ILS 56 e ILS 71. Os genótipos de coloração roxa se sobressaíram na quantidade de potássio e os de coloração creme, na quantidade de fósforo. O consumo de uma porção média de $200 \mathrm{~g}$ de qualquer uma das batatas-doces forneceria $28 \%$ da necessidade de magnésio a crianças de 4 a 8 anos, e em torno de $20 \%$ das necessidades diárias de magnésio e $10 \%$ de potássio para gestantes.

Palavras-chave: Ipomoea batatas (L.) Lam.; Nutrientes; Minerais; Dietética.

\section{Abstract}

The objective of this work was to quantify the minerals present in coloured pulp sweet potato genotypes, selected and cultivated by Embrapa (Empresa Brasileira de Pesquisa Agropecuária), in the southern region of Rio Grande do Sul, Brazil, as well as checking their percentage adequacy for consumption by groups at nutritional risk. The following sweet potato genotypes grown in the Active Germplasm Bank were analysed in triplicate: white pulp (Rubissol, ILS 12, ILS 10 and ILS 24); cream pulp (Cuia, ILS 03 and ILS 44); yellow/orange pulp (Amélia and Beauregard); and purple pulp (ILS 56, ILS 16 and ILS 71). The minerals were quantified by atomic absorption spectrometry and expressed as $\mathrm{mg}$ of the corresponding mineral per $100 \mathrm{~g}^{-1}$ of fresh weight. The percentages of adequacy of the recommended daily intake of each genotype for risk groups (children between 4 and 8 years old and pregnant women between 19 and 30 years old) based on the consumption of an average portion of $200 \mathrm{~g}$ per day, were calculated. The sweet potatoes showed great variation in the minerals amongst the genotypes, and potassium was the most abundant in all of them, especially in the genotypes ILS 44, ILS 56 and ILS 71. The purple coloured genotypes stood out for their potassium contents and the cream coloured genotypes for their phosphorus contents. The consumption of a portion about $200 \mathrm{~g}$ of any sweet potatoes would provide $28 \%$ of the magnesium requirement for children, aged 4 to 8 years, and about $20 \%$ of the daily requirement of magnesium and $10 \%$ of potassium, for pregnant women.

Keywords: Ipomoea batatas (L.) Lam.; Nutrients; Minerals; Dietetics. 


\section{Introdução}

A batata-doce (Ipomoea batatas) ocupa o sétimo lugar na cultura alimentar mundial e o quarto, em países tropicais (FAO, 2004). É uma raiz que se caracteriza pelos seguintes aspectos: rusticidade, facilidade de cultivo, ampla adaptação a diferentes tipos de clima e solo, tolerância à seca, capacidade de adaptação à condição marginal, além de possuir baixo custo de produção (CARDOSO et al., 2005; BRASIL, 2014).

Este alimento, bastante consumido no Brasil, obteve uma produção nacional de 479 mil toneladas no ano de 2013 (FAO, 2004, 2013). A batata-doce é comumente consumida cozida ou assada, mas também pode ser utilizada como matéria-prima na obtenção de doces, farinhas, flocos e féculas (OLIVEIRA ROESLER et al., 2008). Possui também alto valor nutritivo, pelo seu conteúdo de carboidratos, e versatilidade sensorial, em termos de cores de polpa, sabor e textura. As variações de coloração da polpa podem indicar as suas quantidades de $\beta$-caroteno, antocianinas, compostos fenólicos, fibra dietética, ácido ascórbico, ácido fólico e também de sais minerais (WOOLFE, 2008). O interesse por cultivares de batata-doce de polpa colorida está crescendo devido ao seu potencial nos compostos bioativos e nutricionais, e nos possíveis impactos positivos destes na saúde humana (CAMIRE et al., 2009).

Nesse sentido, a batata-doce é considerada um alimento promissor também para erradicação de carências nutricionais em grupos populacionais com deficiência de consumo em calorias ou nutrientes e pessoas com aumento das necessidades, como crianças, mulheres em idade fértil e gestantes, inclusive pessoas esportistas, dada a sua elevada composição nutricional (KEHOE et al., 2015). Estudos em outros países descrevem a batata-doce como excelente fonte de vitaminas do complexo B e vitamina $A$, e de minerais, como ferro, cálcio, potássio, enxofre e magnésio (LOW et al., 2007). Semelhantes às vitaminas, os minerais atuam em processos metabólicos corporais e possuem funções fisiológicas exclusivas na regulação e catalisação de mecanismos celulares e moleculares importantes (BAILEY et al., 2015). Apesar da importância da batata-doce como fonte de minerais, são escassos os estudos sobre sua composição no Brasil.

Nesse sentido, atividades de pesquisa e desenvolvimento integrados são destinadas a melhorar a produção, o armazenamento, as tecnologias de pós-colheita e de processamento de alimentos, incluindo, entre estes, a batata-doce. A melhora da qualidade da cadeia produtiva da batata-doce possibilita agregar valor comercial ao alimento e também qualidade nutricional (BOVELL BENJAMIN, 2007). O melhoramento genético tem permitido a expressão do potencial produtivo do germoplasma selecionado e tem sido amplamente utilizado para selecionar materiais genéticos com elevado potencial de cultivo e de comercialização, além de, muitas vezes, potencializar o teor de micronutrientes nos alimentos selecionados (MILLER; WELCH, 2013).

Com base nisso, objetivou-se quantificar os minerais presentes em genótipos de batata-doce in natura de polpa colorida, selecionados e cultivados pela Empresa Brasileira de Pesquisa Agropecuária no sul do Rio Grande do Sul, bem como verificar o percentual de adequação de consumo para adultos e grupos de risco nutricional.

\section{Material e métodos}

\subsection{Material vegetal}

Acessos genéticos de batata-doce cultivados no Banco Ativo de Germoplasma da Embrapa Clima Temperado das colorações creme: Rubissol, Cuia, ILS 03, ILS 10, ILS 12, ILS 24, ILS 44; alaranjada: Amélia; Iaranja: Beauregard, e roxas: ILS 56, ILS 16, ILS 71 foram estudados. As seleções foram inseridas no banco identificadas pela sigla ILS (Introdução Local Sul), seguida pelo número sequencial de introdução, sendo todas apresentadas com registros sobre o local de coleta e informações sobre o produtor que as forneceu.

As batatas-doces foram colhidas 140 dias após o plantio, tendo sido, então, retiradas as sujidades; em seguida, foram transportadas até o Núcleo de Alimentos da Embrapa Clima Temperado, Pelotas-RS, onde foram retiradas as cascas e cortadas em pedaços de aproximadamente cinco centímetros, para sua posterior liofilização. As amostras foram liofilizadas em equipamento Liobrás, modelo L101, e foram trituradas em moinho (Willey), para a obtenção de pó. A digestão foi realizada em equipamento de bloco digestor (Kjeldahl) e as análises, realizadas em triplicata.

\subsection{Quantificação de minerais}

Para a quantificação de micronutrientes (Cu, Fe, Mn, Zn), foi transferido $1,0 \mathrm{~g}$ da amostra para tubos de digestão adicionados de $6 \mathrm{~mL}$ de ácido nítrico concentrado, sendo deixados de repouso por 24 horas. Foram colocados em blocos de digestão aquecidos entre $80{ }^{\circ} \mathrm{C}$ e $90^{\circ} \mathrm{C}$ por 30 minutos, depois se aumentou a temperatura para $120^{\circ} \mathrm{C}$ a $130{ }^{\circ} \mathrm{C}$ até restar entre $0,5 \mathrm{~mL}$ e $1 \mathrm{~mL}$ de solução. Após 10 minutos de repouso, foi adicionado 1,0 mL de ácido perclórico concentrado, aquecendo-se novamente por 2 horas a solução, em $180^{\circ} \mathrm{C}$ a $190^{\circ} \mathrm{C}$, até total desprendimento de gases. Após digestão, o volume obtido foi diluído e aferido com água deionizada em balão volumétrico de $20 \mathrm{~mL}$. Para leitura do branco, utilizaram-se $6 \mathrm{~mL}$ de ácido nítrico e $1 \mathrm{~mL}$ de ácido perclórico, sendo que todas as amostras foram lidas em equipamento de absorção atômica (SILVA, 2009).

Para quantificação de macronutrientes $(\mathrm{Ca}, \mathrm{Mg}, \mathrm{K}, \mathrm{P})$, foi pesado 0,2 $\mathrm{g}$ de amostra e então transferido para tubos de digestão, sendo adicionados: 0,7 g de mistura digestora $\left(\mathrm{CuSO}_{4}+\mathrm{Na}_{2} \mathrm{SO}_{4}\right), 1,0 \mathrm{~mL}$ de peróxido de 
hidrogênio e $2 \mathrm{~mL}$ de ácido sulfúrico. Foram colocados em blocos de digestão aquecidos entre $160^{\circ} \mathrm{C}$ e $180^{\circ} \mathrm{C}$ por 30 minutos, aumentando-se a temperatura para $350^{\circ} \mathrm{C}$ a $375^{\circ} \mathrm{C}$, até a solução clarear numa cor amarelo esverdeado. Após esse procedimento, foram mantidos à mesma temperatura, por 60 minutos. Após a digestão, o volume obtido foi diluído e aferido com água deionizada em balão volumétrico de $20 \mathrm{~mL}$. Para leitura do branco, foi utilizado $1 \mathrm{~mL}$ de peróxido de hidrogênio e $2 \mathrm{~mL}$ de ácido sulfúrico. Para determinação de $\mathrm{Ca}$ e $\mathrm{Mg}$, foi retirado 1,0 $\mathrm{mL}$ da amostra e acrescidos $4 \mathrm{~mL}$ de óxido de lantânio 0,1\%, sendo então adicionados de água quantificada através de testes de diluição e lidos em equipamento de absorção atômica. Para determinação de $\mathrm{K}$, foi retirado $1 \mathrm{~mL}$ de amostra e adicionado de água quantificada através de testes de diluição; em seguida, o volume obtido foi lido em equipamento de absorção atômica. Para o P, foi utilizada uma alíquota de $1 \mathrm{~mL}$ e adicionados $2 \mathrm{~mL}$ de água destilada, $3 \mathrm{~mL}$ de solução P-B ( $\mathrm{HCl} 0,87 \mathrm{M}$ e (NH4)6Mo7024.4 $\left.\mathrm{H}_{2} \mathrm{O} 0,38 \%\right), 3$ gotas de solução P-C (ácido 1-amino-2-naftol-4-sulfônico, sulfito de sódio e metabissulfito de sódio); em seguida, foram agitados e deixados em repouso por 30 minutos, sendo lidos em 660 nm (SILVA, 2009).

Para a quantificação de minerais, foram agrupados os genótipos das batatas-doces conforme as suas cores de polpa.

\subsection{Percentual de adequação para grupos de risco}

O percentual de adequação mineral foi obtido a partir do cálculo da quantidade de determinado mineral em uma porção média de consumo diário de 200 g, em diferentes genótipos de batata-doce in natura, em relação à necessidade diária recomendada com base nas
Dietarys References Intakes (NAS, 2001, 2004), para dois grupos de risco, crianças entre 4 e 8 anos, e gestantes entre 19 e 30 anos. Para isso, utilizou-se a Equação 1:

$\%$ Adequação $=\frac{\text { Massa de minerais em } 200 \mathrm{~g} \text { de cada batata-doce } * 100}{\text { Valor de recomendação diáriapara minerais }}$

\subsection{Análise estatística}

Os dados foram digitados em planilha do Excel versão 2010 e submetidos à análise de variância, e as médias foram comparadas pelo teste de Tukey a 5\% de probabilidade de erro, no Winstat - versão 2.11. As análises de variância foram realizadas no Stata 13.0.

\section{Resultados e discussão}

Há um crescente interesse no papel dos micronutrientes para otimização da saúde e na prevenção ou tratamento de doenças; isso acontece, em grande parte, pelo aumento do conhecimento e da compreensão das funções bioquímicas desses nutrientes (SHENKIN, 2006). Os minerais devem ser fornecidos constantemente por uma alimentação equilibrada e adequada a cada idade; porém, a deficiência de nutrientes, isolados ou simultâneos, como vitaminas e minerais, é preocupante, especialmente em mulheres grávidas, pelo aumento da demanda, e em crianças de até 5 anos, que são mais vulneráveis (BAILEY et al., 2015).

Neste estudo, inicialmente, foi descrita a quantificação mineral de genótipos e seleções de batata-doce; em seguida, foi verificada a contribuição média para a ingestão diária recomendada em adultos; por fim, obteve-se o percentual de adequação de consumo diário de uma porção média de batata-doce, conforme recomendação diária de ingestão para gestantes e crianças.

Os resultados da Tabela 1 demonstraram que as concentrações de cálcio variaram desde 16,75 (ILS 56) até

Tabela 1. Composição mineral conforme lista de nutrientes em diferentes genótipos de batata-doce in natura, expressa em miligrama do mineral correspondente a 100 gramas de batata in natura (base úmida). Embrapa Clima Temperado, Pelotas, RS, 2016.

\begin{tabular}{|c|c|c|c|c|c|c|c|c|c|}
\hline \multirow{2}{*}{ Genótipo } & \multirow{2}{*}{ Cor da polpa } & \multicolumn{8}{|c|}{ Composição mineral* $e^{* *}$} \\
\hline & & $\mathrm{Ca}$ & Mg & $\mathbf{K}$ & $\mathbf{P}$ & $\mathrm{Cu}$ & $\mathrm{Fe}$ & Mn & $\mathbf{Z n}$ \\
\hline Beauregard & Laranja & $26,93^{\text {de }}$ & $32,45^{c}$ & $169,18^{9}$ & $3,77^{e}$ & $0,022^{\text {de }}$ & $0,066^{\mathrm{fg}}$ & $0,034^{e f}$ & $0,025^{\text {ef }}$ \\
\hline Amélia & Alaranjada & $26,83^{e}$ & $23,23^{\dagger}$ & $356,75^{b c}$ & $4,61^{\mathrm{bcd}}$ & $0,026^{c d}$ & $0,094^{\mathrm{cd}}$ & $0,043^{d}$ & $0,030^{d}$ \\
\hline Cuia & Creme & $21,23^{f}$ & $29,28^{\text {de }}$ & $395,25^{a}$ & $4,83^{\mathrm{bc}}$ & $0,032^{a b c}$ & $0,115^{b}$ & $0,069^{a}$ & $0,045^{\mathrm{ab}}$ \\
\hline Rubissol & Creme & $41,69^{b}$ & $46,48^{a}$ & $305,52^{d}$ & $7,44^{\mathrm{a}}$ & $0,033^{a}$ & $0,100^{c}$ & $0,052^{c}$ & $0,042^{b}$ \\
\hline ILS 03 & Creme & $43,63^{a}$ & $28,16^{\text {de }}$ & $351,62^{c}$ & $7,14^{\mathrm{a}}$ & $0,035^{\mathrm{a}}$ & $0,125^{b}$ & $0,029^{\text {efg }}$ & $0,033^{\text {cd }}$ \\
\hline ILS 10 & Branca & $38,39^{c}$ & $30,64^{\mathrm{cd}}$ & $376,84^{\mathrm{ab}}$ & $7,01^{a}$ & $0,027^{\mathrm{bcd}}$ & $0,070^{e f}$ & $0,036^{\text {de }}$ & $0,029^{d e}$ \\
\hline ILS 12 & Creme & $28,10^{d}$ & $24,35^{\dagger}$ & $336,53^{c}$ & $6,89^{a}$ & $0,033^{a b}$ & $0,082^{\text {de }}$ & $0,054^{b c}$ & $0,037^{\circ}$ \\
\hline ILS 16 & Roxa & $44,78^{a}$ & $42,05^{b}$ & $289,07^{d}$ & $4,62^{\mathrm{bcd}}$ & $0,02^{a}$ & $0,152^{\mathrm{a}}$ & $0,063^{a}$ & $0,049^{a}$ \\
\hline ILS 24 & Branca & $18,88^{9}$ & $29,22^{\text {de }}$ & $222,03^{f}$ & $5,39^{b}$ & $0,018^{e}$ & $0,070^{e f}$ & $0,066^{a}$ & 0,029 de \\
\hline ILS 44 & Creme & $20,82^{f}$ & $18,42^{\mathrm{g}}$ & $352,26^{c}$ & $4,42^{\text {cde }}$ & $0,010^{f}$ & $0,062^{\mathrm{fg}}$ & $0,027^{\mathrm{fg}}$ & $0,020^{f}$ \\
\hline ILS 56 & Roxa & $16,75^{\mathrm{h}}$ & $27,25^{e}$ & $389,99^{a}$ & $6,96^{a}$ & $0,023^{\text {de }}$ & $0,095^{c}$ & $0,021^{g}$ & $0,029^{d e}$ \\
\hline ILS 71 & Roxa & $21,80^{f}$ & $19,64^{\mathrm{g}}$ & $254,18^{e}$ & $4,00^{\mathrm{de}}$ & $0,017^{e}$ & $0,055^{\mathrm{g}}$ & $0,062^{\mathrm{ab}}$ & $0,023^{f}$ \\
\hline
\end{tabular}

*Dados apresentados são valores médios de três repetições expressos em miligrama do mineral correspondente a 100 gramas de batata in natura. Ca: cálcio; Mg: magnésio; K: potássio; P: Fósforo; Cu: Cobre; Fe: Ferro; Mn: Manganês; Zn: Zinco; ${ }^{\star *}$ Médias (n=3) seguidas da mesma letra minúscula na coluna não diferem entre si pelo teste de Tukey $(p<0,05)$. 
44,78 (ILS 16) mg/100 g de batata-doce, sendo a ILS 16 a seleção destaque, por apresentar a maior concentração deste mineral, seguida da ILS 03. Estudo com batatas-doces africanas apresentou variação de 23,04 até 29,97 mg/100 g de cálcio, entre as 12 cultivares analisadas (SANOUSSI et al., 2016). Esse mineral é fundamental para o organismo, devido ao seu papel na coagulação sanguínea, na contração muscular, na função neurológica, na formação de ossos e dentes, e nos processos metabólicos (SENGA KITUMBE et al., 2013).

Os valores de magnésio apresentaram ampla variação, desde a cultivar Rubissol, com maior concentração (46,48 mg/100 g), seguida da seleção ILS 16, sendo a menor concentração encontrada na ILS 44 (18,42 mg/100 g). Tais valores mostram-se similares aos encontrados em outro estudo (SANOUSSI et al., 2016). A deficiência de magnésio no organismo humano tem sido relacionada à interferência no metabolismo dos carboidratos (SALES et al., 2014). É importante que os níveis de magnésio estejam adequados no organismo humano, para prevenção de diversas doenças, incluindo as cardiovasculares e sistêmicas. Inclusive, recentemente, a baixa ingestão regular desse mineral foi associada à maior chance de desenvolvimento de depressão, em adultos (TARLETON; LITTENBERG, 2015).

A média total de minerais, cálcio e magnésio, nos genótipos de batata-doce, apresentou quantidades superiores aos referidos na Tabela de Composição de Alimentos (TACO), que demonstram uma média de $21 \mathrm{mg}$ e 17 mg, respectivamente, de cálcio e de magnésio, em $100 \mathrm{~g}$ de batata-doce crua (UNICAMP, 2011).

Para o mineral potássio, foram observadas variações entre 169,18 (Beauregard) e 395,25 (Cuia) mg/100 g de batata-doce, valores superiores aos encontrados anteriormente por outros estudos (LAURIE et al., 2015; SANOUSSI et al., 2016). Nas raízes da batata-doce, o potássio foi o mineral presente em maior quantidade em todos os genótipos avaliados. O potássio está presente na maioria das células, sendo requerido em várias reações celulares e mostrando-se importante na transmissão de impulsos nervosos, na contração do músculo esquelético, na conversão de glicose em glicogênio e na função hormonal (NAVARRA; SHANKIN-COHEN, 2004).

O conteúdo de fósforo apresentou variação de 7,44 (Rubissol) a 3,77 (Beauregard) mg/100 g de batata-doce, sendo inferior a outras cultivares (SANOUSSI et al., 2016). Esse mineral é fundamental por participar do metabolismo energético, na regulação da atividade proteica, no balanço ácido-básico, na formação de dentes e ossos, e na transmissão genética (NAVARRA; SHANKIN-COHEN, 2004).

As concentrações dos microminerais cobre, ferro, manganês e zinco foram baixas, dentre as cultivares estudadas. Estes são essenciais por exercerem função de cofatores enzimáticos no organismo. A quantidade de cobre variou de 0,010 (ILS 44) a 0,035 (ILS 03) mg/100 g, valores estes bem abaixo dos encontrados na literatura, que apresenta dados entre 0,25 e 0,65 mg/100 g de batata-doce (AWAY et al., 2013). A atividade de enzimas, como a catalase e a tirosina, dependem da presença do cobre, sendo esse mineral um importante cofator de enzimas antioxidantes (RANJKESH et al., 2011).

O ferro apresentou valores entre 0,055 (ILS 71) a 0,152 (ILS 16) mg/100 g de batata-doce. Comparando-se com outro estudo, essas concentrações foram bem inferiores, sendo reportados valores de 1,03 a 1,40 mg/100 g, quando avaliados vários genótipos coloridos de batata-doce (AWAY et al., 2013). O ferro é um metal envolvido na regulação do crescimento e é parte integrante de proteínas e enzimas, que mantêm funções fisiológicas, sendo que a maior parte do ferro está contida na hemoglobina, cuja função é o transporte de oxigênio (JOMOVA; VALKO, 2011). Estudo com 12 cultivares diferentes das variedades aqui apresentadas apresentou maior teor de ferro nas batatas-doces de polpa laranja (SANOUSSI et al., 2016); porém, no presente estudo, esse teor foi superior entre as cultivares de polpas creme e roxa.

Já o conteúdo de manganês nos genótipos de batata-doce apresentou variação de 0,021 (ILS 56) a 0,069 (Cuia) mg/100 g. O manganês atua nas carboxilases e nas lipases envolvidas no metabolismo de carboidratos e lipídeos.

A concentração de zinco variou de 0,020 a 0,049 mg/100 g, sendo inferior aos valores encontrados no estudo de Sanoussi et al. (2016). Esse mineral é essencial para o desenvolvimento normal e a função celular e molecular, colaborando para um bom funcionamento do sistema imunológico (BAILEY et al., 2015; PRASAD, 2008).

Cabe destacar que todos minerais são essenciais para a vida humana e necessários para o funcionamento adequado do organismo, formando parte das enzimas (LUIS et al., 2014). Estudo recente demonstrou que a batata-doce possui uma boa relação sódio-potássio e cálcio-magnésio, mostrando ser um alimento adequado para evitar doenças, como hipertensão e diabetes (SANOUSSI et al., 2016).

A variação da concentração de minerais entre os genótipos pode ser influenciada por diversos fatores, como a variedade, a área de produção, o solo e o clima, as práticas agrícolas, o armazenamento e as condições de transporte e comercialização (LUIS et al., 2014).

A Tabela 2 demonstra a influência da cor da polpa das batatas-doces estudadas na quantidade de minerais. O cálcio foi o único mineral que apresentou médias estatisticamente diferentes entre as cores de polpa, sendo superior nas batatas-doces de polpa creme, seguidas das polpas brancas. No estudo de 
Tabela 2. Composição mineral conforme lista de nutrientes em diferentes cores de polpa de batata-doce in natura, expressa em miligrama do mineral correspondente a 100 gramas de batata in natura (base úmida). Embrapa Clima Temperado, Pelotas, RS, 2016.

\begin{tabular}{ccccccccc} 
Cor da & \multicolumn{7}{c}{ Composição mineral } \\
polpa & $\mathbf{C a}$ & $\mathbf{M g}$ & $\mathbf{K}$ & $\mathbf{P}$ & $\mathbf{C u}$ & $\mathbf{F e}$ & $\mathbf{M n}$ \\
Laranja & 26,88 & 27,84 & 262,97 & 4,19 & 0,02 & 0,08 & 0,04 & $\mathbf{Z n}$ \\
Creme & 31,09 & 29,34 & 348,24 & 6,14 & 0,03 & 0,10 & 0,05 & 0,04 \\
Branca & 28,63 & 29,93 & 299,44 & 6,20 & 0,02 & 0,07 & 0,05 & 0,03 \\
Roxa & 27,78 & 29,65 & 311,08 & 5,19 & 0,02 & 0,10 & 0,05 & 0,03 \\
p-valor* & 0,05 & 0,30 & 0,29 & 0,86 & 0,36 & 0,52 & 0,74 & 0,52 \\
\hline
\end{tabular}

*Análise de variância. Ca: cálcio; Mg: magnésio; K: potássio; P: Fósforo; Cu: Cobre; Fe: Ferro; Mn: Manganês; Zn: Zinco.

Tabela 3. Percentual de adequação mineral diária em diferentes genótipos de batata-doce in natura (base úmida), conforme grupo etário de crianças (4 a 8 anos) e gestantes (19 a 30 anos), baseado em uma porção média de batata-doce equivalente a $200 \mathrm{~g}$ diários. Embrapa Clima Temperado, Pelotas, RS, 2016.

\begin{tabular}{|c|c|c|c|c|c|c|c|c|c|c|c|c|c|}
\hline \multirow{2}{*}{\multicolumn{2}{|c|}{ Minerais/Grupo }} & \multicolumn{12}{|c|}{ Adequação mineral diária conforme genótipo de batata-doce (\%) } \\
\hline & & \multirow{2}{*}{ Beau. } & \multirow{2}{*}{ Am. } & \multirow{2}{*}{ Cuia } & \multirow{2}{*}{ Rub. } & \multirow{2}{*}{$\begin{array}{c}\text { ILS } \\
03\end{array}$} & \multirow{2}{*}{$\begin{array}{c}\text { ILS } \\
10\end{array}$} & \multirow{2}{*}{$\begin{array}{c}\text { ILS } \\
12\end{array}$} & \multirow{2}{*}{$\begin{array}{c}\text { ILS } \\
16\end{array}$} & \multirow{2}{*}{$\begin{array}{l}\text { ILS } \\
24\end{array}$} & \multirow{2}{*}{$\begin{array}{r}\text { ILS } \\
44\end{array}$} & \multirow{2}{*}{$\begin{array}{r}\text { ILS } \\
56\end{array}$} & \multirow{2}{*}{$\begin{array}{l}\text { ILS } \\
71\end{array}$} \\
\hline & & & & & & & & & & & & & \\
\hline \multirow{2}{*}{$\mathrm{Ca}$} & Criança* & 5,4 & 5,4 & 4,2 & 8,3 & 8,7 & 7,7 & 5,6 & 9,0 & 3,8 & 4,2 & 3,4 & 4,4 \\
\hline & Gestante\& & 5,4 & 5,4 & 4,2 & 8,3 & 8,7 & 7,7 & 5,6 & 9,0 & 3,8 & 4,2 & 3,4 & 4,4 \\
\hline \multirow{2}{*}{$\mathrm{Mg}$} & Criança* & 49,9 & 35,7 & 45,0 & 71,5 & 43,3 & 47,1 & 37,5 & 64,7 & 45,0 & 28,3 & 41,9 & 30,2 \\
\hline & Gestante $^{\&}$ & 18,5 & 13,3 & 16,7 & 26,6 & 16,1 & 17,5 & 13,9 & 24,0 & 16,7 & 10,5 & 15,6 & 11,2 \\
\hline \multirow{2}{*}{ K } & Criança* & 8,9 & 18,8 & 20,8 & 16,1 & 18,5 & 19,8 & 17,7 & 15,2 & 11,7 & 18,5 & 20,5 & 13,4 \\
\hline & Gestante\& & 7,2 & 15,2 & 16,8 & 13,0 & 15,0 & 16,0 & 14,3 & 12,3 & 9,4 & 15,0 & 16,6 & 10,8 \\
\hline \multirow{2}{*}{$P$} & Criança* & 1,5 & 1,8 & 1,9 & 3,0 & 2,9 & 2,8 & 2,8 & 1,8 & 2,2 & 1,8 & 2,8 & 1,6 \\
\hline & Gestante $^{\&}$ & 1,1 & 1,3 & 1,4 & 2,1 & 2,0 & 2,0 & 2,0 & 1,3 & 1,5 & 1,3 & 2,0 & 1,1 \\
\hline \multirow{2}{*}{$\mathrm{Cu}$} & Criança* & 10,0 & 11,8 & 14,5 & 15,0 & 15,9 & 12,3 & 15,0 & 9,1 & 8,2 & 4,5 & 10,5 & 7,7 \\
\hline & Gestante $^{\&}$ & 4,4 & 5,2 & 6,4 & 6,6 & 7,0 & 5,4 & 6,6 & 4,0 & 3,6 & 2,0 & 4,6 & 3,4 \\
\hline \multirow{2}{*}{$\mathrm{Fe}$} & Criança* & 1,3 & 1,9 & 2,3 & 2,0 & 2,5 & 1,4 & 1,6 & 3,0 & 1,4 & 1,2 & 1,9 & 1,1 \\
\hline & Gestante ${ }^{\&}$ & 0,5 & 0,7 & 0,9 & 0,7 & 0,9 & 0,5 & 0,6 & 1,1 & 0,5 & 0,5 & 0,7 & 0,4 \\
\hline \multirow{2}{*}{$\mathrm{Mn}$} & Criança* & 4,5 & 5,7 & 9,2 & 6,9 & 3,9 & 4,8 & 7,2 & 8,4 & 8,8 & 3,6 & 2,8 & 8,3 \\
\hline & Gestante $^{\&}$ & 3,4 & 4,3 & 6,9 & 5,2 & 2,9 & 3,6 & 5,4 & 6,3 & 6,6 & 2,7 & 2,1 & 6,2 \\
\hline \multirow{2}{*}{$\mathrm{Zn}$} & Criança* & 1,0 & 1,2 & 1,8 & 1,7 & 1,3 & 1,2 & 1,5 & 2,0 & 1,2 & 0,8 & 1,2 & 0,9 \\
\hline & Gestante\& & 0,5 & 0,5 & 0,8 & 0,8 & 0,6 & 0,5 & 0,7 & 0,9 & 0,5 & 0,4 & 0,5 & 0,4 \\
\hline
\end{tabular}

*Criança: de 4 a 8 anos; ${ }^{*}$ Gestante: 19 a 30 anos. Beau: Beauregard; Am: Amélia; Rub: Rubissol; Ca: cálcio (mg); Mg: magnésio (mg); K: potássio (mg); P: Fósforo (mg); Cu: Cobre (mg); Fe: Ferro (mg); Mn: Manganês (mg); Zn: Zinco (mg).

Laurie et al. (2012), verificou-se que batatas-doces alaranjadas apresentaram teores superiores de cálcio e magnésio, quando comparadas às de cor creme. Ikanone e Oyekan (2014) verificaram valores de ferro e zinco maiores, e cálcio, cobre e magnésio, menores que as batatas-doces estudadas no Brasil, quando comparadas às irlandesas; porém, também constataram um leve aumento do conteúdo mineral após a cocção das batatas, por cozimento ou fritura, indicando que o conteúdo mineral se modifica após o tratamento térmico de batatas-doces. Estudo realizado com outras cultivares, no Quênia, indica que a polpa alaranjada contém níveis mais elevados de ferro, cobre e potássio (AWAY et al., 2013), porém as batatas dessa coloração, no presente estudo, não foram as mais expressivas nos referidos nutrientes. Ishida et al. (2000) também encontraram percentuais maiores que os encontrados no atual estudo. O cálcio, diferente do atual estudo, assim como ferro e magnésio, foi superior também nas cultivares alaranjadas em estudo recente (SANOUSSI et al., 2016). As batatas-doces de coloração roxa, ricas em antocianinas (ADEBAMOWO et al., 2015), apesar de não haver significância estatística, apresentaram quantidades expressivas de magnésio e potássio.

De acordo com os dados obtidos na quantificação, foi possível verificar a contribuição média dos genótipos de batata-doce para a ingestão diária recomendada (IDR), segundo a Recommended Dietary Allowances (RDA) (NAS, 2001, 2004), em diferentes genótipos de batata-doce in natura, conforme grupo etário de crianças entre 4 e 8 anos, e gestantes entre 19 e 30 anos, e baseando-se em uma porção média de $200 \mathrm{~g}$ batata-doce de consumo diário (Tabela 3).

Ao verificar a quantidade de minerais, conforme necessidade de ingestão diária dos grupos de indivíduos 
selecionados, destaca-se a elevada quantidade de magnésio em todos os genótipos de batata-doce, o que facilitaria, ao grupo de crianças de 4 a 8 anos, consumir mais de $25 \%$ da necessidade desse mineral ao ingerir qualquer um dos genótipos de batata-doce, exceto Amélia e ILS 44. Para o grupo de gestantes, a adequação das necessidades ficaria em torno de $10 \%$, para todos os genótipos.

O consumo diário de uma porção média de batata-doce forneceria baixo conteúdo mineral de ferro. Entretanto, não se analisou a biodisponibilidade desse mineral, que está na forma não heme na batata-doce.

Já para os minerais potássio e fósforo, os percentuais de adequação das necessidades diárias para crianças variaram de 8,9 a $20,8 \%$, e de 1,5 até $3,0 \%$, respectivamente. Cabe destacar que os genótipos Cuia (creme), ILS 56 (roxa) e ILS 10 (branca) apresentaram valores superiores, especialmente de potássio, o que contribuiria para atingir parte das necessidades diárias desse grupo de indivíduos. Ressalta-se que o consumo adequado de potássio está associado à redução do risco de acidente vascular cerebral em mulheres adultas (ADEBAMOWO et al., 2015).

Cabe ressaltar que a biodisponibilidade destes minerais não foi avaliada neste estudo e esta pode ser alterada por diversas variáveis, como alimento ingerido concomitante, teor de polifenóis da batata-doce e teor de vitamina C ou outras vitaminas, que podem aumentar a biodisponibilidade dos minerais analisados (CHRISTIDES et al., 2015).

Ao considerar o consumo de $200 \mathrm{~g}$ de batata-doce num dia, este forneceria mais de $28 \%$ das necessidades diárias de magnésio, em torno de 15\% de potássio e 10\% de cobre, para crianças. Para gestantes, forneceria em torno de $20 \%$ das necessidades diárias de magnésio e 10\% de potássio. Isso leva a considerar que as batatas-doces analisadas contribuem para a nutrição de gestantes e de crianças, junto a uma alimentação adequada e saudável. Em estudo comparando dados de conteúdo mineral com o consumo de $150 \mathrm{~g}$ batata doce biofortificada, demonstrou-se que este forneceria mais de $10 \%$ de zinco, ferro e magnésio das necessidades diárias para crianças de 4 a 8 anos de idade (LAURIE et al., 2015).

Cabe mencionar, como limitação deste estudo, que, em algumas comparações das concentrações de minerais encontradas com dados da literatura, utilizaram-se métodos diferentes; porém, essa comparação sempre foi mantida com a mesma unidade de medida (em mg/100 g), assim como foram considerados somente os resultados expressos em base úmida. Além disso, o consumo excessivo de alguns minerais, como cobre, ferro, zinco e manganês, pode ser prejudicial à saúde humana; porém, para que isso ocorra, o consumo teria de ser aproximadamente dez vezes maior que a recomendação, ingestão esta quase impossível de atingir, com base na dieta atual da população brasileira.

\section{Conclusão}

Pode-se concluir que batatas-doces são uma boa fonte de minerais para a dieta, especialmente por serem ricas em potássio, e que o genótipo de batata-doce exerce influência sobre a concentração de minerais em seu conteúdo. Como fonte de potássio, a Cuia, a ILS 56 e a ILS 10 foram destaque. A coloração teve pouca influência para a concentração de minerais entre os genótipos, sendo que apenas as batatas-doces de coloração creme tiveram maior teor de cálcio que as de outras cores.

O consumo de uma porção média de $200 \mathrm{~g}$ de qualquer uma das batatas-doces forneceria a crianças de 4 a 8 anos, mais de $28 \%$ da necessidade de magnésio. Para gestantes, o consumo dessa mesma porção diária forneceria em torno de $20 \%$ das necessidades diárias de magnésio e $10 \%$ de potássio.

Portanto, estes resultados são relevantes para programas de melhoramentos genéticos com foco na melhoria das cultivares de batata-doce, em um determinado conteúdo mineral.

\section{Agradecimentos}

À Empresa Brasileira de Pesquisa Agropecuária Clima Temperado e ao Projeto Quintais Orgânicos de Frutas (CGTEE/FINEP) pelo apoio no desenvolvimento desse projeto e pela concessão das bolsas de estudo.

\section{Referências}

ADEBAMOWO, S. N.; SPIEGELMAN, D.; WILLETT, W. C.; REXRODE, K. M. Association between intakes of magnesium, potassium, and calcium and risk of stroke: 2 cohorts of US women and updated meta-analyses. The American Journal of Clinical Nutrition, v. 101, n. 6, p. 1269-1277, 2015. PMid:25948665. http://dx.doi. org/10.3945/ajcn.114.100354.

AWAY, A. K.; NAWIRI, M. P.; NYAMBAKA, H. N. Nutrient variation in colored varieties of Ipomea batatas grown in Vihiga County, Western Kenya. Food Research International, v. 20, n. 2, p. 819-825, 2013.

BAILEY, R. L.; WEST JUNIOR, K. P.; BLACK, R. E. The epidemiology of global micronutrient deficiencies. Annals of Nutrition \& Metabolism, v. 66, p. 22-33, 2015. Supplement 2. PMid:26045325. http://dx.doi.org/10.1159/000371618.

BOVELL-BENJAMIN, A. C. Sweet potato: a review of its past, present, and future role in human nutrition. Advances in Food and Nutrition Research, v. 52, p. 1-59, 2007. PMid:17425943. http://dx.doi.org/10.1016/S1043-4526(06)52001-7.

BRASIL. Ministério da Saúde. Secretaria de Atenção à Saúde. Departamento de Atenção Básica. Guia alimentar para a população brasileira. 2. ed. Brasília: Ministério da Saúde, 2014. $156 \mathrm{p}$. 
Composição mineral em genótipos de batata-doce de polpas coloridas e adequação de consumo para grupos de risco Vizzotto, M. et al.

CAMIRE, M. E.; KUBOW, S.; DONNELLY, D. J. Potatoes and human health. Critical Reviews in Food Science and Nutrition, v. 49, n. 10, p. 823-840, 2009. PMid:19960391. http://dx.doi. org/10.1080/10408390903041996.

CARDOSO, A. D.; VIANA, A. E. S.; RAMOS, P. A. S.; MATSUMOTO, S. N.; AMARAL, C. L. F.; SEDIYAMA, T.; MORAIS, O. M. Avaliação de clones de batata-doce em Vitória da Conquista. Horticultura Brasileira, v. 23, n. 4, p. 911-914, 2005. http://dx.doi.org/10.1590/ S0102-05362005000400009.

CHRISTIDES, T.; AMAGLOH, F. K.; COAD, J. Iron bioavailability and provitamin A from sweet potato- and cereal-based complementary foods. Foods, v. 4, n. 3, p. 463-476, 2015. PMid:28231217. http:// dx.doi.org/10.3390/foods4030463.

FOOD AND AGRICULTURE ORGANIZATION OF THE UNITED NATIONS - FAO. Agricultural data. Rome: FAO, 2004. Disponível em: <http://faostat.fao.org/site/408/DesktopDefault. aspx?PagelD=408>. Acesso em: 16 set. 2016 .

FOOD AND AGRICULTURE ORGANIZATION OF THE UNITED NATIONS - FAO. Production of commodity in selected country. Rome: FAO, 2013. Disponível em: <faostat3.fao.org/browse/Q/ QC/E>. Acesso em: 16 set. 2016.

IKANONE, C. E. O.; OYEKAN, P. O. Effect of boiling and frying on the total carbohydrate, vitamin $\mathrm{C}$ and mineral contents of Irish (Solanun tuberosum) and Sweet (Ipomea batatas) potato tubers. Nigerian Food Journal, v. 32, n. 2, p. 33-39, 2014. http://dx. doi. org/10.1016/S0189-7241(15)30115-6.

ISHIDA, H.; SUZUNOA, H.; SUGIYAMAA, N.; INNAMIB, S.; TADOKOROC, T.; MAEKAWAC, A. Nutritive evaluation on chemical components of leaves, stalks and stems of sweet potatoes (Ipomoea batatas poir). Food Chemistry, v. 68, n. 3, p. 359-367, 2000. http://dx.doi.org/10.1016/S0308-8146(99)00206-X.

JOMOVA, K.; VALKO, M. Importance of iron chelation in free radical-induced oxidative stress and human disease. Current Pharmaceutical Design, v. 17, n. 31, p. 3460-3473, 2011. PMid:21902663. http://dx.doi.org/10.2174/138161211798072463.

KEHOE, S. H.; CHOPRA, H.; SAHARIAH, S. A.; BHAT, D.; MUNSHI, R. P.; PANCHAL, F.; YOUNG, S.; BROWN, N.; TARWANDE, D.; GANDHI, M.; MARGETTS, B. M.; POTDAR, R. D.; FALL, C. H. Effects of a food-based intervention on markers of micronutrient status among Indian women of low socio-economic status. British Journal of Nutrition, v. 113, n. 5, p. 813-821, 2015. PMid:25677713. http://dx.doi.org/10.1017/S000711451400419X.

LAURIE, S. M.; VAN JAARSVELD, P. J.; FABER, M.; PHILPOTT, M. F.; LABUSCHAGNE, M. T. Trans- $\beta$-carotene, selected mineral content and potential nutritional contribution of 12 sweet potato varieties. Journal of Food Composition and Analysis, v. $27, \mathrm{n}$. 2, p. 151-159, 2012. http://dx.doi.org/10.1016/j.jfca.2012.05.005.

LAURIE, S.; FABER, M.; ADEBOLA, P.; BELETE, A. Biofortification of sweet potato for food and nutrition security in South Africa.
Food Research International, v. 76, n. 4, p. 962-970, 2015. http://dx.doi.org/10.1016/j.foodres.2015.06.001.

LOW, J. W.; ARIMOND, M.; OSMAN, N.; CUNGUARA, B.; ZANO, F.; TSCHIRLEY, D. A food-based approach introducing orangefleshed sweet potatoes increased Vitamin A intake and serum retinol concentrations in young children in rural Mozambique. The Journal of Nutrition, v. 137, n. 5, p. 1320-1327, 2007. PMid:17449599.

LUIS, G.; RUBIO, C.; GUTIÉRREZ, A. J.; GONZÁLEZ-WELLER, D.; REVERT, C.; HARDISSON, A. Evaluation of metals in several varieties of sweet potatoes (Ipomoea batatas L.): comparative study. Environmental Monitoring and Assessment, v. 186, n. 1, p. 433-440, 2014. PMid:23979675. http://dx.doi.org/10.1007/ s10661-013-3388-8.

MILLER, D. D.; WELCH, R. M. Food system strategies for preventing micronutrient malnutrition. Food Policy, v. 42, p. 115-128, 2013. http://dx.doi.org/10.1016/j.foodpol.2013.06.008.

NATIONAL ACADEMY OF SCIENCES - NAS. Institute of Medicine. Food and Nutrition Board. Dietary reference intakes for Vitamin A, Vitamin K, Arsenic, Boron, Chromium, Copper, lodine, Iron, Manganese, Molybdenum, Nickel, Silicon, Vanadium, and Zinc. Washington: NAS, 2001.

NATIONAL ACADEMY OF SCIENCES - NAS. Institute of Medicine. Food and Nutrition Board. Dietary Reference intakes for water, Potassium, Sodium, Chloride, and Sulfate. Washington: NAS, 2004.

NAVARRA, T.; SHANKIN-COHEN, W. The encyclopedia of vitamins, minerals and suplements. New York: Facts On File, 2004.

OLIVEIRA ROESLER, P. V. S.; GOMES, S. D.; MORO, E.; KUMMER, S. C. B.; CEREDA, M. P. Produção e qualidade de raiz tuberosa de cultivares de batata-doce no oeste do Paraná. Acta Scientiarum Agronomy, v. 30, n. 1, p. 117-122, 2008.

PRASAD, A. S. Zinc in human health: effect of zinc on immune cells. Molecular Medicine, v. 14, n. 5-6, p. 353-357, 2008. PMid:18385818. http://dx.doi.org/10.2119/2008-00033.Prasad.

RANJKESH, F.; JALISEH, H. K.; ABUTORABI, S. Monitoring the copper content of serum and urine in pregnancies complicated by preeclampsia. Biological Trace Element Research, v. 144, n. 1-3, p. 58-62, 2011. PMid:21487891. http://dx.doi.org/10.1007/ s12011-011-9026-9.

SAlES, C. H.; SANTOS, A. R.; CINTRA, D. E.; COLLI, C. Magnesium-deficient high-fat diet: effects on adiposity, lipid profile and insulin sensitivity in growing rats. Clinical Nutrition, v. 33, n. 5, p. 879-888, 2014. PMid:24182515. http://dx.doi. org/10.1016/j.clnu.2013.10.004.

SANOUSSI, A. F.; ADJATIN, A.; DANSI, A.; ADEBOWALE, A.; SANNI, L. O.; SANNI, A. Mineral composition of ten elites sweet potato (Ipomoea Batatas [L.] Lam.) landraces of Benin. International Journal of Current Microbiology and Applied 
Composição mineral em genótipos de batata-doce de polpas coloridas e adequação de consumo para grupos de risco Vizzotto, M. et al.

Sciences, v. 5, n. 1, p. 103-115, 2016. http://dx.doi.org/10.20546/ ijcmas.2016.501.009.

SENGA KITUMBE, P.; OPOTA ONYA, D.; TAMBA VEMBA, A.; TONA LUTETE, G.; KAMBU KABANGU, O.; COVACI, A.; APERS, S.; PIETERS, C. K. L. CIMANGA KANYANGA, R. Chemical composition and nutritive value study of the seed oil of Adenanthera pavonina L. (Fabaceae) growing in Democratic Republic of Congo. International Journal of Pharm. Tech. Research, v. 5, n. 1, p. 205-216, 2013.

SHENKIN, A. Micronutrients in health and disease. Postgraduate Medical Journal, v. 82, n. 971, p. 559-567, 2006. PMid:16954450. http://dx.doi.org/10.1136/pgmj.2006.047670.
SILVA, F. C. Manual de análises químicas de solos, plantas e fertilizantes. 2. ed. Brasília: Embrapa Informação Tecnológica, 2009.

TARLETON, E. K.; LITTENBERG, B. Magnesium intake and depression in adults. Journal of the American Board of Family Medicine, v. 28, n. 2, p. 249-256, 2015. PMid:25748766. http:// dx.doi.org/10.3122/jabfm.2015.02.140176.

UNIVERSIDADE ESTADUAL DE CAMPINAS - UNICAMP. Núcleo de Estudos e pesquisas em Alimentação - NEPA. Tabela Brasileira de Composição de Alimentos. Campinas: NEPA, 2011.

WOOLFE, J. A. Sweet potato: an untapped food resource. Cambridge: Cambridge University Press, International Potato Centre, 2008. 